\title{
Biomarkers of Ovarian Ageing
}

\author{
Paolo Giovanni Artini
}

\subsection{Introduction}

The ovary is the main regulator of female fertility, and its biologic clock is set to ensure reproductive success during a definite life stage. According to the evolutionary concept that organisms maximize fitness by promoting production of progeny, allocation of resources between reproductive and somatic functions is finely regulated during life [1]. Thus, it has been speculated that the premature ageing of the ovary when compared with somatic organs might result from increased energy demand for maintenance and repair processes in the soma compartment during ageing [1].

According to the human biologic clock, the gradual loss of female fertility becomes more dramatic in the late 30 s with a steep decrease beginning after age 35 , ending in menopause at mean age of 51 years [2]. This would preserve women from the physical stress of pregnancy in advanced age and maximize the length of time they can bear children [3]. As a result, increasing postponement of the first pregnancy represents a crucial factor in the widespread of subfertility in industrialized societies [4]. Given the intrapopulation variability of the reproductive life span [5], it is generally accepted that coping with this issue requires a careful reproductive counselling based on accurate predictive markers.

Ovarian functional decline with ageing has been so far extensively characterized in terms of gradual depletion of ovarian follicles and reduced ability to produce oocytes competent for fertilization and further development [2]. The analysis of the molecular and cellular aspects of follicle ageing would require careful consideration. In fact, oocytes and granulosa cells of primordial follicles might remain in a

P.G. Artini

Division of Gynecology and Obstetrics, Department of Experimental and Clinical Medicine, University of Pisa, Pisa, Italy

e-mail: paolo.artini@med.unipi.it 
'resting' phase for a long time, thus behaving as post-mitotic cells which can be required to start growing after 10-50 years. Furthermore, both primordial and growing follicles become exposed to environmental factors related to the ageing of the ovarian somatic compartment, and finally, the development of a competent oocyte intimately depends on the crosstalk between all compartments in the ovary.

For decades, research on reproductive ageing has been focusing on the so-called quantitative aspect of ovarian ageing, which has led to mathematical models predicting follicle loss on the basis of chronologic age without taking into account biologic markers [6]. When the concept of oocyte ageing as the main determinant of fertility decline has become clear [7], researchers have begun to expand investigations into the whole ovarian microenvironment in search of age-related changes with potential effects on follicle and oocyte competence.

Although it is generally accepted that ageing is a result of both inborn and environmental factors, most of the numerous theories of ageing share the concept that age-associated malfunction results from physiological accumulation of irreparable damage to biomolecules as an unavoidable side effect of normal metabolism and underline the importance of the capability of defensive repair.

More than a decade after the free radical theory of ovarian ageing first proposed by Tarin [8], biological and clinical research has provided numerous evidence that increased reactive oxygen species (ROS), which are among the most important physiological inducers of cellular injury associated with ageing [9], is a main determinant to follicle ageing $[10,11]$. ROS generated by mitochondrial dysfunction is considered the main cause for telomere shortening, chromosomal segregation disorders, maturation and fertilization failures or oocyte/embryo fragmentation [11]. Looking for ROS aetiology and widespread, a relevant role has been ascribed to advanced glycation end products (AGEs), factors that may hamper ovarian stroma vessels, follicular growth, assembly of an efficient system of antioxidant enzymatic defence as well as development of an efficient perifollicular vascularization [12]. Further evidence for ROS in the ovarian follicle was obtained by research on stress signalling pathways in aged granulosa and cumulus cells $[13,14]$. Enzymatic activity and protein level of superoxide dismutase (SOD), the enzyme that reacts with superoxide anion radicals to form oxygen and $\mathrm{H}_{2} \mathrm{O}_{2}$, were found to decrease with age, and lower levels of SOD activity are associated with unsuccessful IVF outcomes. Nevertheless, there are poor evidences for possible benefits from antioxidant treatments in humans, suggesting that further actors are involved in modulating stress adaptive response in the ovary during ageing [15].

\subsection{Biomarkers}

\subsubsection{Antral Follicle Count (AFC)}

The ovarian AFC and ovarian volume (OV) as determined by transvaginal ultrasound examination have been widely evaluated as a marker of ovarian responsiveness (OR) [16]. They are reliable indicators of OR and potential predictors of menopausal age. The intercycle variation of $\mathrm{OV}$ is more pronounced than that of $\mathrm{AFC}$. The AFC is the number of antral follicles between 2 and $10 \mathrm{~mm}$ in size within both ovaries observed on transvaginal ultrasound examination on days $2-3$ of the 
menstrual cycle. The AFC is currently the most reliable ultrasound parameter pre- 69 dicting age at menopause.

\subsubsection{Follicle-Stimulating Hormone (FSH)}

FSH is a glycoprotein produced by the anterior pituitary known to regulate the licle and furthermore regulate the androgen conversion to oestrogen. The ovarian granulosa cells are the target of FSH.

FSH has been studied extensively as a marker of OR; in fact, elevated levels of FSH are the hormonal sign of reproductive ageing. In early follicular phase, FSH starts to increase 10 years before menopause; in fact, FSH levels are influenced by age and body size [17].

\subsubsection{Estradiol (E2)}

The levels of E2 show a continuous decline in sex steroids with advancing age; in fact, E2 levels show an increase in late menopausal transition.

\subsubsection{Luteinizing Hormone (LH)}

The LH levels increase with age as a result of increased pituitary sensitivity to GnRH. During menopausal transition, LH rises slowly, reaching moderately elevated levels in postmenopause. The increase in FSH levels is more than that in LH, because of the loss of inhibin-B and E2 feedback.

\subsubsection{Inhibin-B}

Inhibin-B is a polypeptide produced by the granulosa and theca cells of the developing cohort of antral follicles, whereas inhibin-A is primarily a product of the developing dominant follicle and the corpus luteum. In fact, inhibin-B reflects the ovarian follicle pool and may have paracrine functions influencing folliculogenesis in the ovary. Inhibin-B correlates with age only during a relatively short time before menopausal transition. The levels are influenced by fluctuating ovarian function of late ovarian ageing and throughout the menstrual cycle [18].

\subsubsection{Anti-Müllerian Hormone (AMH)}

$\mathrm{AMH}$ is member of the TGF- $\beta$ superfamily. AMH is produced by the ovarian granulosa cells of preantral and small antral follicles, the number of which is related to the size of the primordial follicle pool, and serum levels of AMH fluctuate minimally throughout the menstrual cycle. AMH is undetectable in the serum until the onset of 
puberty. AMH modulates primordial follicle recruitment by inhibiting the action of FSH on follicle growth and selection. AMH reflects the non-FSH-dependent follicular growth. AMH production disappears during follicular maturation, allowing the follicle to complete the development process during FSH-dependent stages of growth. AMH secretion is independent of other hormones and is expressed a constant level, irrespective of the day of menstrual cycle. Progressive and linear decline until menopause due to a decreasing number of primordial follicle is observed [19].

\section{Conclusions}

Ovarian follicles, oocytes and embryos are constantly challenged by stress and privations and require adaptive responses for their survival. In addition to redox perturbations in the intraovarian microenvironment related to ageing or diseases with an oxidative basis, reproductive cells have to face stress conditions during manipulation during assisted reproductive procedure [20].

Predicting the age of the final menstrual period for the individual woman remains an important goal for clinicians and patients alike. In addition to risk assessment, the prediction of the age of menopause may well predict the age of subfertility and the end of natural fertility. The biological state of the oocyte remains the key element in normal reproduction. The decreasing number of ovarian follicles is accompanied by reduction of oocyte quality. There are many theories explaining the cause of low-quality oocyte, including abnormal vascularization, oxidative stress and imbalance of free radicals; in fact, the formation of AGE is responsible for ageing of the cells. They contribute directly to protein damage, induce a chain of reactions of oxidative stress and increase the inflammatory reactions. Moreover, this paper stresses the prognostic value of clinically used markers evaluating the ovarian reserve, in particular the role of $\mathrm{AMH}, \mathrm{AFC}$ and FSH levels. In conclusion, $\mathrm{AMH}$ is the best current available measure of ovarian reserve and as predictor of ovarian response to stimulation.

\section{References}

1. Kirkwood TB (2005) Understanding the odd science of aging. Cell 120:437-447

2. Broekmans FJ, Knauff EA, te Velde ER, Macklon NS, Fauser BC (2007) Female reproductive ageing: current knowledge and future trends. Trends Endocrinol Metab 18:58-65

3. Cohen AA (2004) Female post-reproductive lifespan: a general mammalian trait. Biol Rev Camb Philos Soc 79:733-750

4. Balasch J, Gratacós E E (2011) Delayed childbearing: effects on fertility and the outcome of pregnancy. Fetal Diagn Ther 29:263-273

5. Te Velde ER, Pearson PL (2002) The variability of female reproductive ageing. Hum Reprod Update 8:141-154

6. Hansen KR, Knowlton NS, Thyer AC, Charleston JS, Soules MR, Klein NA (2008) A new model of reproductive aging: the decline in ovarian non-growing follicle number from birth to menopause. Hum Reprod 23:699-708

7. Sauer MV (1998) The impact of age on reproductive potential: lessons learned from oocyte donation. Maturitas 30:221-225 
8. Tarin JJ (1995) Aetiology of age-associated aneuploidy: a mechanism based on the 'free radi- 144 cal theory of ageing'. Hum Reprod 10:1563-1565 145

9. Harman D (2006) Free radical theory of aging: an update: increasing the functional life span. 146 Ann N Y Acad Sci 1067:10-21

10. Agarwal A, Gupta S, Sharma RK (2005) Role of oxidative stress in female reproduction. Reprod Biol Endocrinol 14:28

11. Lim J, Luderer U (2011) Oxidative damage increases and antioxidant gene expression decreases with aging in the mouse ovary. Biol Reprod 84:775-782

12. Tatone C, Eichenlaub-Ritter U, Amicarelli F (2014) Dicarbonyl stress and glyoxalases in ovarian function. Biochem Soc Trans 42:433-438

13. Ito M, Imai M, Muraki M, Miyado K, Qin J, Kyuwa S et al (2011) GSTT1 is upregulated by oxidative stress through p38-MK2 signaling pathway in human granulosa cells: possible association with mitochondrial activity. Aging 3:1213-1223

14. Matos L, Stevenson D, Gomes F, Silva-Carvalho JL, Almeida H (2009) Superoxide dismutase expression in human cumulus oophorus cells. Mol Hum Reprod 15:411-419

15. Ruder EH, Hartman TJ, Reindollar RH, Goldman MB (2014) Female dietary antioxidant intake and time to pregnancy among couples treated for unexplained infertility. Fertil Steril 101:759-766

16. Hansen KR, Morris JL, Thyer AC, Soules MR (2003) Reproductive aging and variability in the ovarian antral follicle count: application in the clinical setting. Fertil Steril 80(3):577-583

17. Sowers MR, Eyvazzadeh AD, McConnell D et al (2008) Anti-mullerian hormone and inhibin $\mathrm{B}$ in the definition of ovarian aging and the menopause transition. J Clin Endocrinol Metab 93(9):3478-3483

18. Creus M, Peñarrubia J, Fábregues F et al (2000) Day 3 serum inhibin B and FSH and age as predictors of assisted reproduction treatment outcome. Hum Reprod 15(11):2341-2346

19. Tran ND, Cedars MI, Rosen MP (2011) The role of anti-müllerian hormone (AMH) in assessing ovarian reserve. J Clin Endocrinol Metab 96(12):3609-3614

20. Tatone C, Amicarelli F, Carbone MC, Monteleone P, Caserta D, Marci R, Artini PG, Piomboni P, Focarelli R (2008) Cellular and molecular aspects of ovarian follicle ageing. Hum Reprod Update 14:131-142 


\section{Author Queries}

Chapter No.: 6

0002593040

\begin{tabular}{|l|l|l|}
\hline Queries & Details Required & Author's Response \\
\hline AU1 & $\begin{array}{l}\text { Please check if edit to sentence starting "The increase in..." is } \\
\text { okay. }\end{array}$ & Okay \\
\hline AU2 & $\begin{array}{l}\text { Please check if edit to sentence starting "In addition to } \\
\text { redox..." is okay. }\end{array}$ & Okay \\
\hline AU3 & $\begin{array}{l}\text { Refs. [2] and [6] were the same based on the original } \\
\text { manuscirpt. So the duplicate reference has been deleted and } \\
\text { references are renumbered accordingly. Please check. }\end{array}$ & Okay \\
\hline
\end{tabular}

